\title{
A Free-Standing, Thick-Film Piezoelectric Energy Harvester
}

\author{
Swee L. Kok, Neil M. White and Nick R. Harris \\ School of Electronics and Computer Science, University of Southampton, \\ Southampton SO17 1BJ, UK \\ Email: \{slk05r,nmw,nrh\}@ecs.soton.ac.uk
}

\begin{abstract}
In this paper, free-standing structures in the form of cantilevers, fabricated by using a combination of conventional thick-film technology and sacrificial layer techniques, is proposed. These structures were designed to operate as energy harvesters at low-levels of ambient vibration and were characterised using a shaker table over a range of frequencies and acceleration levels. A cantilever with dimensions of $\mathbf{1 3 . 5}$ mm long by $9 \mathrm{~mm}$ wide and total thickness of $192 \mu \mathrm{m}$ was found to have Young's modulus of $3.8 \times 10 \mathrm{~N} / \mathrm{m}^{2}$, effective mass of $0.035 \mathrm{~g}$ and spring constant of $362 \mathrm{~N} / \mathrm{m}$. Samples of length $18 \mathrm{~mm}$ and functional elements (Lead Zirconate Titanate, PZT) of thickness $80 \mu \mathrm{m}$ were found to produce an output voltage of up to $130 \mathrm{mV}$ at their resonant frequency of $229 \mathrm{~Hz}$, for an acceleration level of $0.981 \mathrm{~ms}^{-2}$ when driving into a resistive load of $60 \mathrm{k} \Omega$. The addition of a proof mass was shown to improve the electrical output power generation. In a series of experiments, the electric power generated by a beam having a proof mass of $2.2 \mathrm{~g}$, resulted in a nine-fold improvement of output power compared to a device with no proof mass. The size of the proof mass is also an important factor in determining the output power of the device.
\end{abstract}

\section{INTRODUCTION}

Conventionally, thick-film piezoelectric materials are fabricated and used as sensors and actuators. However, with the improvement of high piezoelectric activity in lead zirconate titanate (PZT), useful electrical energy is generated and can be used in powering a variety of microelectronic devices. The first reported thick-film micro-generator described by White et al [1] was fabricated by printing the functional materials on stainless steel. The device was capable of generating powers up of up to $3 \mu \mathrm{W}$ at $80 \mathrm{~Hz}$ for an acceleration of $225.6 \mathrm{~m} / \mathrm{s}^{2}$. Recently, thin-film and micromachining technologies have also been used in fabricating energy harvesters as reported by Jeon et al and Choi et al [2, 3]. However, these devices were operated at relatively high resonant frequencies $(13.9 \mathrm{kHz})$ and high acceleration levels $\left(252 \mathrm{~m} / \mathrm{s}^{2}\right)$, which are not suitable for harvesting energy from typical ambient environments. These are typically at levels of acceleration in the range $0.05-2$ $\mathrm{m} / \mathrm{s}^{2}$ at frequencies from $10 \mathrm{~Hz}$ to $300 \mathrm{~Hz}$.

A better solution for harvesting low level vibrations is by fabricating thick-film piezoelectric materials in free-standing form, where the functional material can move freely without the constraint of the substrate material. The first thick-film free-standing structures were reported by Stecher, G in 1987 [4], who fabricated a form of circular membrane that was used as pressure sensor.

Free-standing thick-film piezoelectric cantilevers fabricated by a combination of conventional thick-film technology and sacrificial layer techniques will now be described further. The structures were fabricated to have different lengths between $4.5 \mathrm{~mm}$ and $18 \mathrm{~mm}$. They were characterised on a shaker table excited by sinusoidal vibration, at different acceleration levels over a range of different frequencies near to the resonant frequency of the beam. Various sizes of proof mass were attached to a sample of length $13.5 \mathrm{~mm}$ and evaluated to determine the electrical output performance and to estimate the Young's modulus and effective mass and spring constant of the structure.

\section{TYPICAL AMBIENT VIBRATION SOURCES}

There are many possible vibration sources having a wide range of frequencies at various acceleration levels, which are available around us and can be used for harvesting energy for powering low energy microelectronic devices. In order to design piezoelectric micro-generators suitable for the ambient environment, a few typical vibration sources were characterised as shown in Fig. 1.

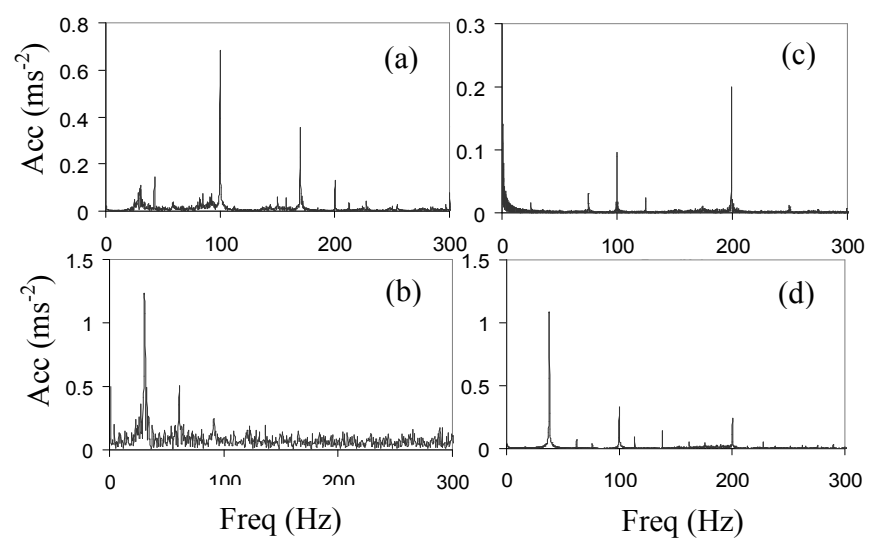

Figure 1. Typical ambient vibration sources measured with an accelerometer and presented in the frequency domain: (a) Microwave casing, (b) engine of a stationary car, (c) kitchen ventilation fan at lower speed and (d) kitchen ventilation fan at higher speed. 
Table 1 shows a summary of the measured vibration sources in terms of peak acceleration levels and resonant frequencies.

TABLE 1. SUMMARIES OF MEASURED VIBRATION SOURCES.

\begin{tabular}{|c|c|c|c|}
\hline \multicolumn{2}{|c|}{ Vibration Sources } & $\begin{array}{l}\text { Acc. } \\
\left(\mathrm{m} / \mathrm{s}^{2}\right)\end{array}$ & $\begin{array}{l}\text { Freq. } \\
(\mathrm{Hz})\end{array}$ \\
\hline \multicolumn{2}{|c|}{ Microwave (Casing) } & 0.68 & 100 \\
\hline \multicolumn{2}{|c|}{ Refrigerator (Coil) } & 0.09 & 100 \\
\hline \multicolumn{2}{|c|}{ Vending machine (Casing) } & 0.12 & 100 \\
\hline \multirow{2}{*}{$\begin{array}{l}\text { Kitchen } \\
\text { ventilation fan }\end{array}$} & Speed I & 0.2 & 200 \\
\hline & Speed II & 1.1 & 38 \\
\hline \multirow{2}{*}{$\begin{array}{l}\text { Desktop } \\
\text { PC }\end{array}$} & Normal operation & 0.21 & 543 \\
\hline & Running CD ROM & 0.26 & 154 \\
\hline \multirow{2}{*}{ Laptop } & Normal operation & 0.26 & 90.2 \\
\hline & Running CD ROM & 0.66 & 43.2 \\
\hline \multirow{2}{*}{$\begin{array}{l}\text { Bus } \\
\text { (floor) }\end{array}$} & Stationary & 0.37 & 111 \\
\hline & $\begin{array}{l}\text { Travelling at } \\
\text { moderate speed }\end{array}$ & 1.04 & 10.8 \\
\hline \multirow{2}{*}{$\begin{array}{l}\text { Stationary Car } \\
(1.0 \mathrm{cc})\end{array}$} & Engine & 1.23 & 30.5 \\
\hline & Dashboard & 0.04 & 30 \\
\hline
\end{tabular}

\section{CANTILEVER Micro-Generator Design}

A cantilever micro-generator was designed based on spring-mass-damper system [5]. When the cantilever is excited with a displacement of $Y(t)$ relative to the system housing, a deflection, $z$ is produced as shown in Fig. 2.

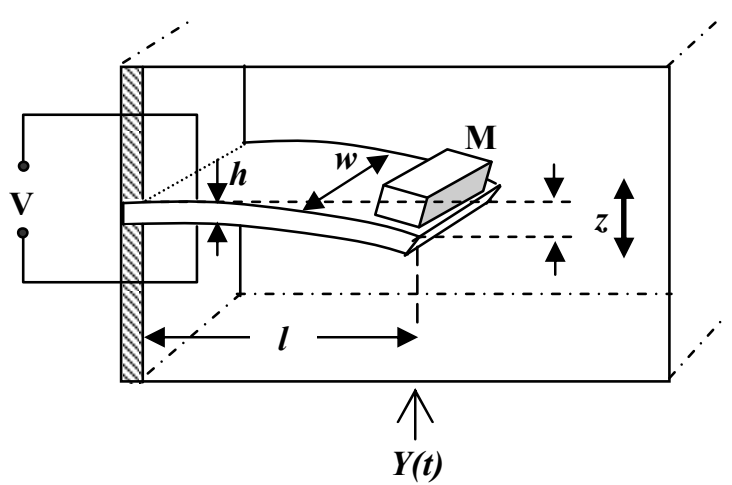

Figure 2. A schematic diagram of a cantilever clamped on one end, with dimensions of length, $l$, width, $w$ and thickness, $h$. The free-standing structure is loaded with a proof mass, $M$, excited with a diplacement of $Y(t)$ and producing a deflection of $z$.
The resonant frequency of a cantilever is determined by the mechanical properties of the structure, which is related to its length, $l$, thickness, $h$, Young's modulus, $\gamma$ and density, $\rho$ given by [6],

$$
f_{n}=\frac{v_{n}^{2}}{2 \pi \sqrt{12}}\left(\frac{h}{l^{2}}\right) \sqrt{\frac{\gamma}{\rho}}
$$

where $v_{n}^{2}$ is the eigenvalue of nth mode of vibration, which is depended on the boundary conditions. The eigenvalue of the fundamental mode of a cantilever beam is 3.52. This equation can be used to estimate the resonant frequency for a uniform beams. However, the dimensions of a cantilever beam change after fabrication because of shrinkage, therefore, the effective mass, $m_{\text {eff }}$ of the materials is used to determine the resonant frequency of the structure, which is given as,

$$
m_{e f f}=\frac{\kappa}{12.71}\left(\frac{v_{n}^{2}}{2 \pi f_{n}}\right)^{2}
$$

The spring constant, $\kappa$ of the structure can be determined by experiments with varying proof masses and excited at its resonant frequency.

When the device is excited at its resonant frequency, the maximum power driving a resistive load is related to the total mass of the system, $m$, input acceleration, $A_{i n}$, angular frequency, $\omega_{n}$ and damping coefficient as,

$$
P_{\max }=\frac{m \zeta_{e} A_{i n}{ }^{2}}{4 \omega_{n}\left(\zeta_{e}+\zeta_{m}\right)^{2}}
$$

The mechanical damping factor, $\zeta_{m}$ is a property of the system which is difficult to control. However, the electrical damping factor, $\zeta_{e}$ can simply be varied by using different resistive load. Once the resistive load is matched with the mechanical damping, maximum energy is transferred from the mechanical to electrical domain. The electrical output power does not increase indefinitely with the proof mass. At some point with additional mass, the damping effect in the structure increases, therefore increasing the energy dissipation, hence decreasing the output power.

\section{FABRICATION TECHNIQUE}

The materials for fabricating the free-standing structures consisted of PZT paste, carbon sacrificial paste, silver/palladium $(\mathrm{Ag} / \mathrm{Pd})$ conductor pastes and alumina substrates. The functional element, PZT pastes were formulated as according to [7], and the carbon pastes similar to that described by Birol et al [8] was used as the sacrificial layer. 
The fabrication process commences by screen-printing a carbon sacrificial layer (Fig. 3), followed by $\mathrm{Ag} / \mathrm{Pd}$ printed over the sacrificial layer as the lower electrode. Eight layers of PZT were then printed and dried in infra-red dryer individually at $140 \mathrm{C}$ for 10 minutes, before a final layer of $\mathrm{Ag} / \mathrm{Pd}$ was printed and dried as the upper electrode layer. The whole composite films were then co-fired together at a peak temperature of $850{ }^{\circ} \mathrm{C}$, holding for 10 minutes, in a multi-zone furnace. During the co-firing process, the carbon sacrificial layer was burnt off in air thus releasing a composite free-standing structure, that breaks free and bends away from the surface of alumina substrates because of the different thermal expansion coefficients between PZT ceramic and $\mathrm{Ag} / \mathrm{pd}$ conductor. Finally, the samples were then polarised at around $3 \mathrm{MV} / \mathrm{m}$ with a temperature of $200{ }^{\circ} \mathrm{C}$ for 30 minutes.

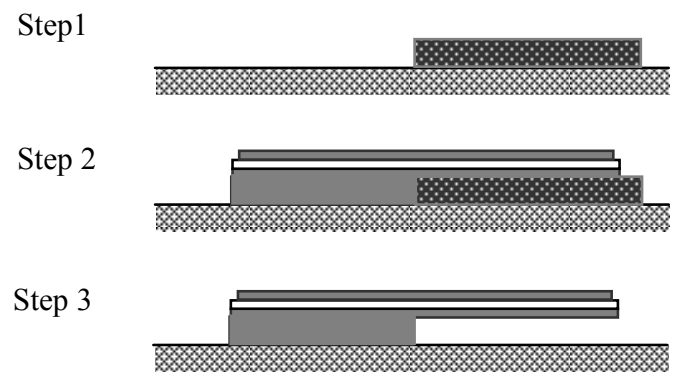

Figure 3. Sacrificial layer technique fabrication steps for releasing a cantilever free-standing structure.

The result of the fabrication is shown in Fig. 4. The fabricated free-standing composite cantilevers were found to shrink by around $10 \%$ from their original design dimensions because of the high negative thermal expansion coefficient of the conductors.

(a)

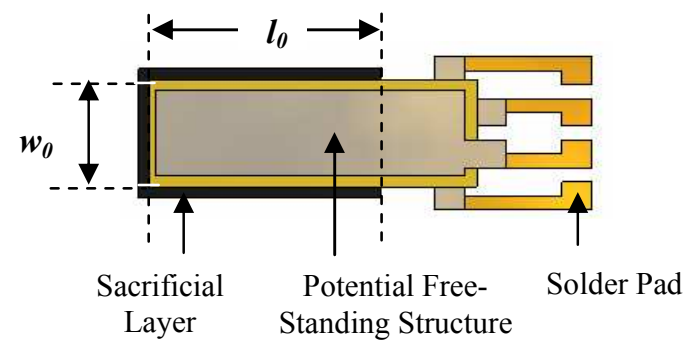

(b)

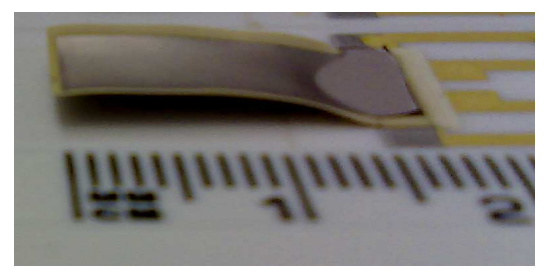

Figure 4. Free-standing cantilever: (a) Design layout and (b) fabricated prototype.

\section{RESULTS AND DISCUSSION}

The resonant frequency of the cantilever decreases with increasing length and added mass according to equations (2) and (3), which were verified experimentally as shown in Fig. 5 (a) and (b) respectively. The density of the sandwich structure of PZT-Ag/Pd was measured at $6240 \mathrm{~kg} / \mathrm{m}^{3}$, which gives an average Young's modulus of $3.8 \times 10 \mathrm{~N} / \mathrm{m}^{2}$. A sample having $13.5 \mathrm{~mm}$ length and $9 \mathrm{~mm}$ width was found to have a spring constant of $362 \mathrm{~N} / \mathrm{m}$ and the calculated effective mass of the cantilever beam is $0.035 \mathrm{~g}$. (a)

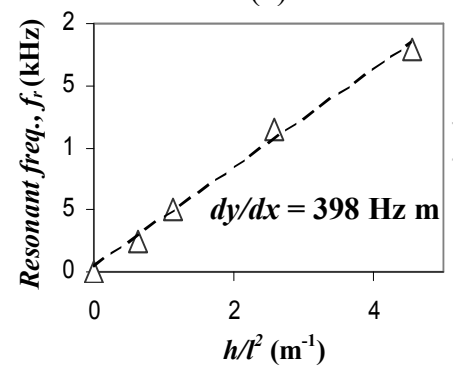

(b)

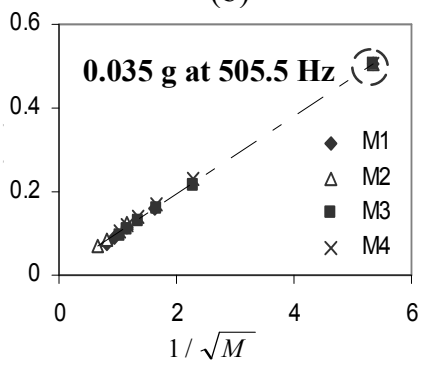

Figure 5. Resonant frequency is inversely proportional to (a) square of length and (b) square root of mass. The gradient of the graph of $f_{r} \mathrm{Vs} h / l^{2}$ can be used to estimate the Young's modulus of the samples. Extrapolation of graph $\mathrm{f}_{\mathrm{r}} \mathrm{Vs} 1 / \sqrt{M}$ can determine the effective mass of the cantilever beam.

The output voltage of the device increases with the length of the cantilever beam as shown in Fig. 6. An open circuit output voltage for a cantilever of length $18 \mathrm{~mm}$ was measured at $130 \mathrm{mV}$ for an acceleration of $0.981 \mathrm{~m} / \mathrm{s}^{2}(0.1$ $\boldsymbol{G})$. However, the voltage dropped to around $20 \mathrm{mV}$ when driving an optimum resistive load of $60 \mathrm{k} \Omega$, which gives an electrical output power of about $7 \mathrm{nW}$.

Higher vibration acceleration levels can improve the electrical output power. The power increases by a factor of more than 25 when accelerated at $9.81 \mathrm{~m} / \mathrm{s}^{2}(1 \boldsymbol{G})$, as shown in Fig. 7. However, a higher acceleration level induces a nonlinearity for power generated by the cantilever structures, where the fundamental resonant frequency was found to be shifted to a lower frequency as the acceleration increases and also due to the fact that the acceleration level is not consistent in the ambient vibration source. Therefore microgenerators with a wider band of resonant frequencies have to be designed to harvest a wider range of different and inconsistent acceleration levels of ambient vibration.

The output power can be increased by attaching a proof mass at the tip of a piezoelectric cantilever. Larger masses produced more power, to an extent. Excessive proof masses, however, can result in energy dissipation through damping effects in the structure. The dimensions of the proof mass are also an important factor in determining the output power. From the experiments conducted, a proof mass that had its centre of mass focused on the tip of the beam and spread 
across the width of the beam, produced the most output power, which is shown by a proof mass, $M 1$ with dimensions of $9 \mathrm{~mm}$ width, $2.5 \mathrm{~mm}$ length and $1 \mathrm{~mm}$ thickness compare to other proof mass as shown in Fig. 8. This is because, in this configuration, more stress was induced when the cantilever was vibrated at its resonant frequency.

\section{CONCLUSION}

This is the first time that thick-film free-standing structures, in the form of a cantilever, have been fabricated by a combination of thick-film and sacrificial layer techniques. The structures were designed to operate in an ambient environment to harvest energy from low acceleration levels and frequencies. In a series of experiments with different cantilever lengths and attaching different proof masses, the mechanical properties, Young's modulus and spring constant of the free-standing structures were determined. Because of the fact that, the devices were not identical to the desired design dimensions, the effective mass of the composite structures is an important parameter to determine their resonant frequencies. Owing to nonlinear effects and the inconsistency of acceleration levels of ambient vibration sources, the design of energy harvesters having wider band of resonant frequencies is desirable. The addition of a proof mass improves the output power to some extent, but the effectiveness decreased for large inertial masses. Although the powers generated from the vibration devices are relatively small $\left(270 \mathrm{nW}\right.$ at $\left.9.81 \mathrm{~m} / \mathrm{s}^{2}\right)$, they have the potential to be improved further i.e. by increasing the thickness of the functional elements.

\section{ACKNOWLEDGMENT}

The PhD scholarship from Universiti Teknikal Malaysia Melaka is gratefully acknowledged.

\section{REFERENCES}

[1] N.M. White, P. Glynne-Jones, and S.P. Beeby, "A novel thick-film piezoelectric micro-generator," Smart Mater. Struct, vol. 10, pp. 850852, 2001.

[2] Y.B. Jeon, R. Sood, J. Jeong, and S.G. Kim, "MEMS power generator with transverse mode thin film PZT," Sensor and Actuators A, vol. 122, pp. 16-22, 2005.

[3] W. Choi, Y. Jeon, J.H. Jeong, R. Sood, and S. Kim, "Energy harvesting MEMS device based on thin film piezoelectric cantilevers," J. Electroceramics, vol. 17(2), pp. 543-548, Dec 2006.

[4] G. Stecher, "Free supporting structures in thick-film technology: A substrate integrated pressure sensor," $6^{\text {th }}$ European Microelectronics Conf. Bournemouth, pp. 421-427, 1987.

[5] C.B. Williams, and R.B. Yates, "Analysis of a micro-electric generator for microsystems," Transducers 95/Eurosensors IX, pp. 369-372, 1995.

[6] J. Merhaut, Theory of electroacoustics, McGraw-Hill, New York, 1981.

[7] R. Torah, "Optimisation of the piezoelectric properties of thick-film piezoceramic devices," PhD thesis, University of Southampton, 2004.

[8] H. Birol, T. Maeder, and P. Ryser, "Fabrication of LTCC microfluidic devices using sacrificial carbon layers," J. Appl. Ceram. Technol., vol. 2, pp. 345-354, 2005.

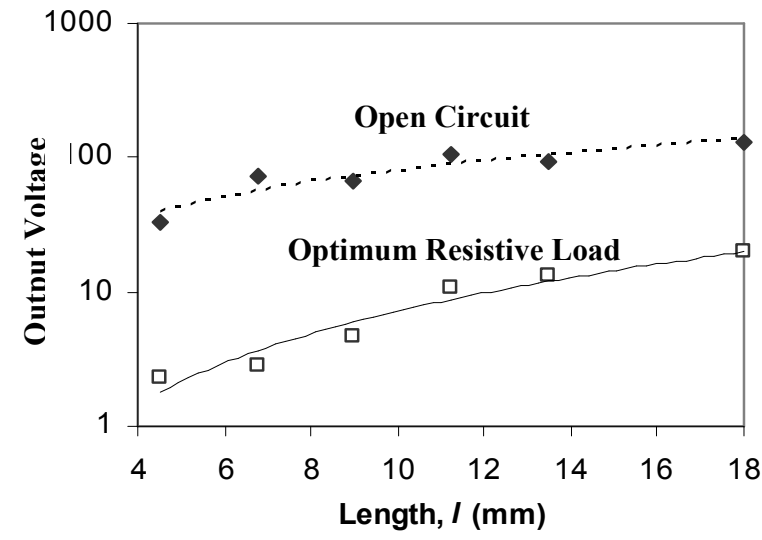

Figure 6. Output voltage as a function of length for the cantilever, with open circuit test and with optimum resistive load test for sample with length $18 \mathrm{~mm}$, accelerated at $0.981 \mathrm{~m} / \mathrm{s}^{2}$.

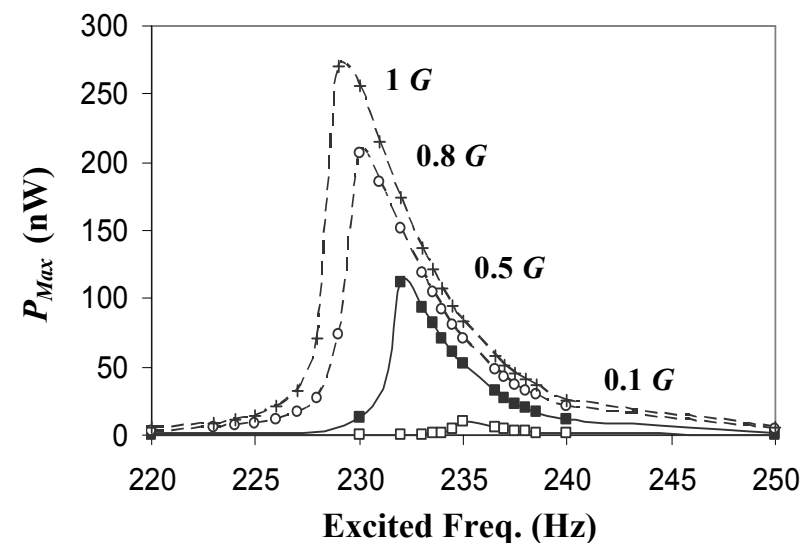

Figure 7. Resonant frequency and output power change as acceleration level changes. $\left(1 \boldsymbol{G}=9.81 \mathrm{~m} / \mathrm{s}^{2}\right)$.

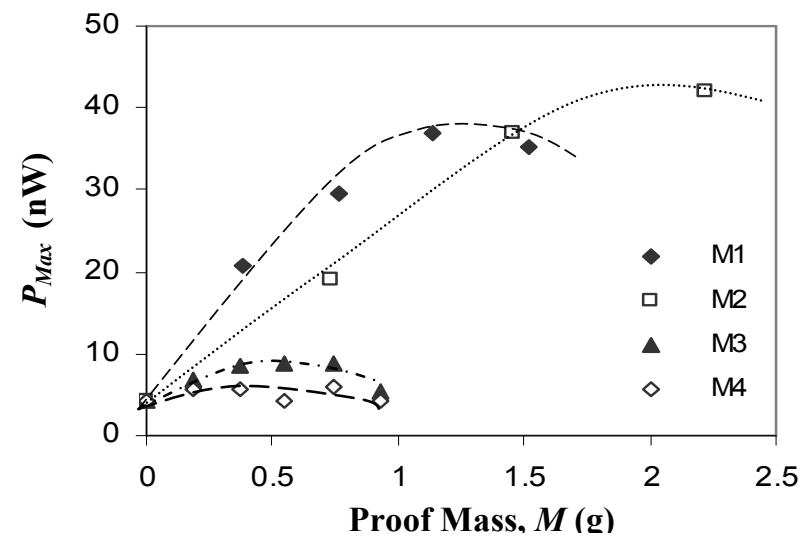

Figure 8. Output power of a cantilever with different proof mass weights and dimensions: width $\times$ length $\times$ thickness $(\mathrm{M} 1=9 \times 2.5 \times 1, \mathrm{M} 2=9 \times 5$ $\times 1, \mathrm{M} 3=4.5 \times 2.5 \times 1$ and $\mathrm{M} 4=2.5 \times 4.5 \times 1) \mathrm{mm}$. 